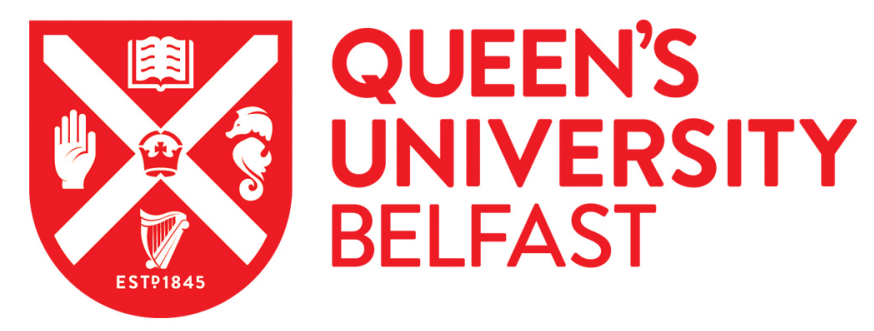

\title{
Deoxygenation in anisole decomposition over bimetallic catalysts supported on HZSM-5
}

\author{
Zhang, J., Fidalgo, B., Wagland, S., Shen, D., Zhang, X., \& Gu, S. (2019). Deoxygenation in anisole \\ decomposition over bimetallic catalysts supported on HZSM-5. Fuel, 238, 257-266. \\ https://doi.org/10.1016/j.fuel.2018.10.129
}

\author{
Published in: \\ Fuel
}

\section{Document Version:}

Peer reviewed version

\section{Queen's University Belfast - Research Portal:}

Link to publication record in Queen's University Belfast Research Portal

\section{Publisher rights}

Copyright 2018 Elsevier.

This manuscript is distributed under a Creative Commons Attribution-NonCommercial-NoDerivs License

(https://creativecommons.org/licenses/by-nc-nd/4.0/), which permits distribution and reproduction for non-commercial purposes, provided the author and source are cited.

\section{General rights}

Copyright for the publications made accessible via the Queen's University Belfast Research Portal is retained by the author(s) and / or other copyright owners and it is a condition of accessing these publications that users recognise and abide by the legal requirements associated with these rights.

Take down policy

The Research Portal is Queen's institutional repository that provides access to Queen's research output. Every effort has been made to ensure that content in the Research Portal does not infringe any person's rights, or applicable UK laws. If you discover content in the Research Portal that you believe breaches copyright or violates any law, please contact openaccess@qub.ac.uk. 


\title{
1 Deoxygenation in anisole decomposition over bimetallic
}

\section{catalysts supported on HZSM-5}

\author{
Jiajun Zhang ${ }^{a, b, c}$, Beatriz Fidalgo c , Stuart Wagland ${ }^{c}$, Dekui Shen ${ }^{a, *}$, Xiaolei Zhang ${ }^{b, *}$, \\ Sai $\mathrm{Gu}^{\mathrm{d}}$ \\ * Corresponding author: D.S., e-mail address: 101011398@seu.edu.cn \\ X.Z., email address: xiaolei.zhang@qub.ac.uk
}

a Key Laboratory of Energy Thermal Conversion and Control of Ministry of Education, Southeast University, Nanjing, China

b School of Mechanical and Aerospace Engineering, Queen's University Belfast, Belfast, United Kingdom

c School of Water, Energy and Environment, Cranfield University, Cranfield, United Kingdom

${ }^{d}$ Faculty of Engineering and Physical Sciences, University of Surrey, Surrey, United Kingdom

\section{Abstract:}

This work investigated the deoxygenation reaction in anisole decomposition over HZSM-5 (HZ(25)) zeolite supported bimetallic catalysts to produce benzene, toluene and xylene (BTX). Experiments were performed in order to evaluate the synergistic effect between the two active metals with the focus on the effect of temperature, metal type, and metal loading ratio. Experimental results showed that $1 \% \mathrm{Ni}-1 \% \mathrm{Mo} / \mathrm{HZ}(25)$ led to both the highest BTX yield (i.e. 30.0 wt.\%) and selectivity (i.e. $83.7 \%$ ). On the contrary, bimetallic catalysts containing Fe were less effective in promoting the BTX production. It was identified that the optimum temperature for BTX production over 
$1 \% \mathrm{Ni}-1 \% \mathrm{Mo} / \mathrm{HZ}(25)$ catalysts was $500^{\circ} \mathrm{C}$. Characterization of fresh and spent catalysts showed microcrystal particles of bi-metal loadings highly dispersed on the zeolite surface, and some agglomeration of metallic particles were also observed. Large amount of carbonaceous deposit was observed on the spent catalysts mainly in the form of amorphous. Density Functional Theory (DFT) modelling was carried out in order to study the adsorption energy of anisole and phenol molecules onto $\mathrm{Ni}-\mathrm{Mo}, \mathrm{Ni}$ Fe and Mo-Fe surfaces; and the interactions between phenol molecule and bimetal surfaces were further analysed. All the analysed bimetal surfaces exhibited strong interactions with the adsorbed molecule. Ni-Mo surface declined electrons energy levels mainly around $1.5 \mathrm{eV}$ in the adsorbate molecule and released the highest adsorption energy; while Ni-Fe and Mo-Fe surface led to more electrons exchange with the adsorbate during the adsorption. The modelling results agreed well with experiments by revealing that the strong binding between phenolic compounds (Phs) and the Ni-Mo based catalysts bimetal surface would lead to a higher BTX production in the deoxygenation reaction in the decomposition of anisole.

Abbreviations: BTX, benzene, toluene and xylene; Phs, phenolic compounds; AHs, aromatic hydrocarbons; PAHs, polycyclic aromatic hydrocarbons

Key words: lignin; catalytic decomposition; deoxygenation; anisole; bimetallic supported catalyst; phenolic compounds

\section{Introduction}

In the context of the bio-based economy, lignin is a major source of aromatic

47 compounds [1-3]. Fast pyrolysis of lignin followed by bio-oil upgrading is a promising route for retrieving aromatic hydrocarbons (AHs) for further application as fuels and fuel additives [4-6]. Methoxy compounds abundantly exist in primary liquid products 
derived from fast pyrolysis of lignin, and the catalytic deoxygenation is favourable for their upgrading into AHs compounds [7]. Anisole (or methoxybenzene) is typically used as model compound of the methoxyl-based lignin-derived compounds, since the methoxy functionality is the only one present in the molecule [8]. The decomposition of anisole is a two-step process which consists of transmethylation and deoxygenation reactions [9-11]. The first step, transmethylation, primarily yields methyl-containing phenolics (Phs) and subsequently aids the formation of AHs [12-16]. During the deoxygenation step, the Phs further react to produce AHs, naphthenic hydrocarbons and even cycloalkanes [9-11]. Catalysts consisting of active metals dispersed on a solid support have showed favourable catalytic activity on the fast pyrolysis of lignin and the upgrading of the derived bio-oil for the production of $\mathrm{AHs}[11,17,18]$. It has been identified that acid zeolite (i.e. HBeta, HZSM-5 etc.) is the most widely investigated support, although other supports have also been studied including metal oxides (i.e. $\mathrm{SiO}_{2}, \mathrm{Al}_{2} \mathrm{O}_{3}$ etc.) and carbon nanofibers [19-23]. Transition metals have exhibited high catalytic active for the reforming process [19,24-26].

Deoxygenation during the catalytic decomposition of anisole has been largely investigated over single noble metal catalyst supported on an inert solid [19,22,27-30]. The reaction over bi-functional catalysts, i.e. a base metal and an acid solid support, has been paid less attention. The literature on the deoxygenation over bi-functional catalysts with two metals deposited on an acid solid support is even scarcer. However, acid solid supported bimetallic catalysts are of great interest to be applied to the catalytic reforming of bio-oil. This is because the second metal can act as a promoter in the catalyst simultaneously favouring for the yield and selectivity of desired products, and impeding the polycondensation reactions of the aromatics [31]. Significant research on the activity of these catalysts in deoxygenation reaction during the catalytic 
decomposition of model compounds, such as anisole, is required in order to properly assess the effect on lignin-derived bio-oil.

This work aims to investigate the deoxygenation reaction in the decomposition of anisole over zeolite supported bimetallic catalysts for the production of the BTX fraction (benzene, toluene, and xylene). Our previous study has reported the excellent performance of $1 \% \mathrm{Ni} / \mathrm{HZ}(25)$ and $1 \% \mathrm{Mo} / \mathrm{HZ}(25)$ in the decomposition of anisole [32], besides, our modelling work also revealed that $\mathrm{Ni}$ and Mo led to high adsorption energy in anisole adsorption, and Fe resulted in a low energy adsorption [33]. In this study, combinations of $\mathrm{Ni}$, Mo and $\mathrm{Fe}$ active metal sites were evaluated. Based on previous experimental work, severe carbonaceous deposit was observed over $\mathrm{Ni}$ and Mo based catalysts [32]. Fe is used in this study to tune the strong adsorption of catalysts and alleviate the severe deposit, so the loading ratio of $\mathrm{Fe}$ is kept the same as $\mathrm{Ni}$ and $\mathrm{Mo}$. Anisole decomposition experiments were run in a fluidized bed reactor to evaluate the effect of temperature, type of bimetallic catalyst, and metal loading ratio on the BTX yield and selectivity. Finally, DFT modelling was carried out to reveal effects of alloy loadings on the decomposition of reactants in microscopic scale by analysing the interaction of reactant molecules and bimetallic surfaces.

\section{Materials and methods}

\subsection{Materials}

Anisole was supplied by Aladdin Reagents Co., Ltd. The HZSM-5 (Si/Al=25, HZ(25)) zeolite catalyst was provided by Nankai University Catalyst Co., Ltd, China. Chemicals used for the synthesis of the catalysts, i.e. nickel nitrite hexahydrate $\left(\mathrm{Ni}\left(\mathrm{NO}_{3}\right)_{2} \cdot 6 \mathrm{H}_{2} \mathrm{O}\right)$, ammonium molybdate tetrahydrate $\left(\left(\mathrm{NH}_{4}\right)_{6} \mathrm{Mo}_{7} \mathrm{O}_{24} \cdot 4 \mathrm{H}_{2} \mathrm{O}\right)$, iron nitrate nonahydrate $\left(\mathrm{Fe}\left(\mathrm{NO}_{3}\right)_{3} \cdot 9 \mathrm{H}_{2} \mathrm{O}\right)$ and citric acid, were supplied by Aladdin Reagents Co., Ltd. The chemicals used for calibration in GC-MS were supplied by Aladdin Reagents Co., Ltd. 
100 Analytical purity chemicals were used. Standard gaseous species, $\mathrm{N}_{2}$, and $\mathrm{H}_{2}$ used for

101 the calibration and operation of GC-FID were supplied by Nanjing Shangyuan Industrial

102 Gas Plant at a purity of $99.999 \%$.

103

104

105

106

107

108

109

110

111

112

113

114

115

116

117

118

119

120

121

122

123

124

125

\subsection{Methods}

\subsubsection{Catalyst preparation and characterisation}

Bimetallic catalysts were synthesized by wet impregnation of the support, $H Z(25)$, with aqueous solutions of the metal precursor, i.e. $\mathrm{Ni}\left(\mathrm{NO}_{3}\right)_{2} \cdot 6 \mathrm{H}_{2} \mathrm{O},(\mathrm{NH} 4)_{6} \mathrm{Mo}_{7} \mathrm{O}_{24} \cdot 4 \mathrm{H}_{2} \mathrm{O}$ or $\mathrm{Fe}\left(\mathrm{NO}_{3}\right)_{3} \cdot 9 \mathrm{H}_{2} \mathrm{O}$ depending on the targeted active metal (see Supplementary Material S1 for full details). It is worth mentioning that citric acid $(\sim 20 \mathrm{~g})$ was used for dissolving the precursors of Mo-Fe due to its ability to ligate the metals and inhibit precipitate formation [34]. The impregnation mixtures were stirred with a magnetic stirrer for $24 \mathrm{~h}$ at room temperature $\left(\sim 25^{\circ} \mathrm{C}\right)$. Water was removed by evaporation at $80{ }^{\circ} \mathrm{C}$ and dried at $110{ }^{\circ} \mathrm{C}$ for $12 \mathrm{~h}$, followed by calcination in air at $500^{\circ} \mathrm{C}$ for $6 \mathrm{~h}$ in a muffle furnace. The calcined catalyst precursors were subsequently crushed and sieved to a particle size range between $60-80$ mesh. The catalysts were reduced in-situ with 25 vol.\% $\mathrm{H}_{2} / \mathrm{N}_{2}$ (total flow rate of $500 \mathrm{~mL} / \mathrm{min}$ ) for $2 \mathrm{~h}$ before the experiments. Reduction temperature was $600^{\circ} \mathrm{C}$ in the case of $\mathrm{Ni}-\mathrm{Fe} / \mathrm{HZ}(25)$ catalyst $[35,36]$, and $800^{\circ} \mathrm{C}$ for both $\mathrm{Ni}-\mathrm{Mo} / \mathrm{HZ}(25)$ and $\mathrm{Mo-Fe} / \mathrm{HZ}(25)$ [37-39]. Zeolite supported bimetallic catalysts with various metal loadings were prepared. They were denoted as $\mathrm{x} \% \mathrm{M}-\mathrm{y} \% \mathrm{~N} / \mathrm{HZ}(25)$, where $\mathrm{M}(=\mathrm{Ni}$ or $\mathrm{Mo})$ and $\mathrm{N}(=\mathrm{Mo}$ or $\mathrm{Fe})$ are the active metals, $\mathrm{x}$ is the loading ratio of $M$, and $y$ is the loading ratio of $N$. The following catalysts supported on $H Z(25)$ were synthesized and tested: $0.5 \% \mathrm{Ni}-1 \% \mathrm{Mo}, 1 \% \mathrm{Ni}-1 \% \mathrm{Mo}, 1 \% \mathrm{Ni}-0.5 \mathrm{Mo} \%, 1 \% \mathrm{Ni}-1 \% \mathrm{Fe}$ and $1 \%$ Mo- $1 \% \mathrm{Fe}$.

Both fresh (reduced) and spent bimetal/HZ(25) catalysts were analyzed by TEM-EDS in order to investigate the morphology of metal active sites and carbonaceous deposits on the zeolite support, and to determine the existing elements on the sample surface. 
The specimens were prepared by ultrasonic dispersion of catalyst samples in ethanol

127 before dropping the suspension to a copper/nickel grid. A TEM Tecnai G2 T20 from 128 FEI Ltd was used for the analyses of catalyst sample. Images of the microstructure, the relevant selected area electron diffraction (SAED) patterns, and Fast Fourier Transform

130 (FFT) images of the specimens were acquired. Energy Dispersive Spectrometer (EDS) tests were performed using Genesis 2000 from EDAX Ltd.

\subsubsection{Experiment}

133 Experiments were carried out in the bench scale fluidised bed reactor (Diameter*Height $134 \mathrm{~mm}=32 \mathrm{~mm} \times 600 \mathrm{~mm})$; further details of the rig can be found in literature $[10,32]$. 135 Nitrogen was used as fluidising gas. The minimum fluidisation velocity $\left(U_{m f}\right)$ was $0.027 \mathrm{~m} / \mathrm{s}$ in all experiments, and it was determined as described in literature [40]. The actual experimental flow velocity was adjusted by means of cold experiments, and set to approximately two times the $U_{m f}$. In each experiment, $50 \mathrm{~g}$ of fresh catalyst were placed inside the reactor and fluidised by a $\mathrm{N}_{2}$ flow rate of $154 \mathrm{~L} / \mathrm{h}$. A total amount of $8.3 \mathrm{~g}$ of liquid anisole was placed in a syringe pump at the beginning of the experiment and pumped into the reactor at a constant flow rate. Anisole flow rate and reaction time were $50 \mathrm{~g} / \mathrm{h}$ and $10 \mathrm{~min}$, respectively. The outflow stream was passed through a three stages quench traps to collect the liquid product. The effect of type of bimetal active sites was investigated by experiments carried out over $1 \% \mathrm{Ni}-1 \% \mathrm{Mo} / \mathrm{HZ}(25), 1 \% \mathrm{Ni}-1 \% \mathrm{Fe} / \mathrm{HZ}(25), \quad 1 \% \mathrm{Mo}-$ $1 \% \mathrm{Fe} / \mathrm{HZ}(25)$ at $500^{\circ} \mathrm{C}$. Experiments over $1 \% \mathrm{Ni}-1 \% \mathrm{Mo} / \mathrm{HZ}(25)$ at $400{ }^{\circ} \mathrm{C}, 500{ }^{\circ} \mathrm{C}$ and $600{ }^{\circ} \mathrm{C}$ were performed in order to evaluate the effect of temperature. The effect of the bimetal loadings was investigated by the experiments carried out over $1 \% \mathrm{Ni}$ $1 \% \mathrm{Mo} / \mathrm{HZ}(25), 1 \% \mathrm{Ni}-0.5 \% \mathrm{Mo} / \mathrm{HZ}(25)$ and $0.5 \% \mathrm{Ni}-1 \% \mathrm{Mo} / \mathrm{HZ}(25)$ at $500^{\circ} \mathrm{C}$. Details of the operating conditions for each experiment are given in Table 1. 
151 After diluting to a constant volume of $150 \mathrm{~mL}$, the collected liquid fraction was analysed

152 by GC-MS in an Agilent GC7890 gas chromatograph-mass spectrometer equipped with 153 a capillary column DB-5ms (30 $\mathrm{m} \times 250 \mu \mathrm{m} \times 0.25 \mu \mathrm{m})$. The injector temperature was $154270^{\circ} \mathrm{C}$. The oven temperature was increased from $40{ }^{\circ} \mathrm{C}$ (held for $3 \mathrm{~min}$ ) to $180{ }^{\circ} \mathrm{C}$ 155 (held for $2 \mathrm{~min}$ ) at a heating rate of $5{ }^{\circ} \mathrm{C} / \mathrm{min}$, and then heated at a rate of $10^{\circ} \mathrm{C} / \mathrm{min}$ up to $280^{\circ} \mathrm{C}$ and held for $2 \mathrm{~min}$. The running time for each GC-MS analysis was $45 \mathrm{~min}$.

157 The mass spectrometer was operated in electron ionization (EI) mode at $70 \mathrm{eV}$ and the 158 spectra were obtained from $\mathrm{m} / \mathrm{z} 35-550$. The column was calibrated with external 159 standards, and the products were quantified by total ion and identified using the 160 database of NIST library database. The amount of carbonaceous deposits on the spent catalyst was determined by thermogravimetric analysis with a SETSYS-1750 CS 162 Evolution TG Instrument. Approximately $15 \mathrm{mg}$ of sample were charged and heated 163 from room temperature $\left(\sim 25^{\circ} \mathrm{C}\right)$ up to $900^{\circ} \mathrm{C}$ at a heating rate of $20^{\circ} \mathrm{C} / \mathrm{min}$ and air flow 164 rate of $20 \mathrm{~mL} / \mathrm{min}$. The sample was kept at $900^{\circ} \mathrm{C}$ for $15 \mathrm{~min}$ to ensure total burn-out of 165 the carbonaceous deposits. Non-condensable gaseous products were analysed in a 166 GC-FID equipped with a SE54 column. $1 \mu \mathrm{L}$ of gas sample was injected into the 167 injector kept at $270^{\circ} \mathrm{C}$. Helium at a flow rate of $6.3 \mathrm{~mL} / \mathrm{min}$ was used as carrier gas. 168 The initial column temperature was $40^{\circ} \mathrm{C}$ (equilibration time of $2 \mathrm{~min}$ ), and the maximum temperature was $300^{\circ} \mathrm{C}$. Total analysis time was $45 \mathrm{~min}$. The mass of liquid 170 fraction, carbon deposit fraction and gas fraction were determined after each 171 experiment. The liquid, carbon deposits and gas yields were determined as a 172 percentage of the initial mass of anisole. The standard deviation of the liquid and 173 carbonaceous deposit yields were evaluated by the repeating experiments; further 174 details are provided in Supplementary Material S2. Based on the analyses, bulk 175 difference over $1 \mathrm{wt} . \%$ for liquid yields and over $4 \mathrm{wt} . \%$ for sold yields were mainly considered in this study. 


\subsubsection{DFT Modelling}

178 The first-principle density functional theory plus dispersion (DFT-D) calculations were 179 implemented in the $\mathrm{DMol}^{3}$ module available in Materials Studio 2016 from BIOVIA $180[41,42]$. The double numerical plus polarization (DNP) basis set was used to calculate the valence orbital of all the atoms, including a polarization p-function on all hydrogen atoms. The numerical basis sets in $\mathrm{DMol}^{3}$ was utilised because they minimize or even

183 eliminate basis set superposition error (BSSE), contrary to Gaussian basis sets, in 184 which BSSE can be a serious problem [43,44]. The generalized gradient corrected approximation (GGA) [45] treated by the Perdew-Burke-Ernzerhof (PBE) exchangecorrelation potential with long-range dispersion correction via Grimme's scheme was used for the calculations [46]. The self-consistent field (SCF) procedure was used with a convergence threshold of $10^{-6}$ au on the energy and electron density. Geometry optimizations were performed with a convergence threshold of $0.002 \mathrm{Ha} / \AA$ on the gradient, $0.005 \AA$ on displacements, and $10^{-5} \mathrm{Ha}$ on the energy. The real-space global cut-off radius was set to $5 \AA$. No symmetry constraints were used for any cluster models. All the adsorbent models were based on doped slabs of bimetal crystals. Moreover, the models exclude the zeolite support in order to avoid its influence and solely investigate the effect of the bimetals. Pre-adsorption and post-adsorption models were established for the adsorption of anisole and phenol molecules, as two of the most frequent compounds interacting with the metal surface during the anisole decomposition. Adsorbates were placed paralleled to the adsorbent as shown in Supplementary Material S12 to S14. Geometry optimization was implemented to every model before energy was calculated. The adsorption energy was determined by the energy difference of the system before and after the adsorption process. All the energies were calculated at $0 \mathrm{~K}$ in the modelling. More detailed analyses of the 
202 interactions between phenol and the bimetal surfaces were carried out, since Phs are

203 the actual reactants in the deoxygenation reaction.

\section{Results and discussion}

\subsection{Effect of the type of metal combination on deoxygenation reaction} over bimetal/HZ(25) catalysts

Experiments with $1 \% \mathrm{Ni}-1 \% \mathrm{Mo} / \mathrm{HZ}(25), 1 \% \mathrm{Ni}-1 \% \mathrm{Fe} / \mathrm{HZ}(25)$ and $1 \% \mathrm{Mo}-1 \% \mathrm{Fe} / \mathrm{HZ}(25)$ catalysts were carried out at $500^{\circ} \mathrm{C}$ (experiments DO2, DO6 and DO7 respectively in Table 1) to investigate the effect of the bimetal type on the deoxygenation stage of the decomposition of anisole. The anisole conversion and grouped yields of liquid, gas and solid (carbonaceous deposits) products are shown in Table 1. Anisole conversion was $100 \%$ for the three experiments. The products mainly consisted of liquids and carbonaceous deposits, with the gas fraction being negligible. These gas products

214 primarily contained alkanes and olefins, as shown in Supplementary Material S8.

215 Regardless the bimetal catalyst used, similar yields of the liquid products (ranging from 34.5 wt. $\%$ to 38.7 wt. $\%$ ) and the carbonaceous deposits (ranging from $61.0 \mathrm{wt} \%$ to 63.9 wt. \%) were obtained.

The effect of the type bimetal/ $\mathrm{HZ}(25)$ catalysts on the liquid product distribution obtained from the deoxygenation reaction in the anisole decomposition process is shown in Fig. 1. Liquid products comprised AHs and Phs. In all cases, AHs mainly consisted of the BTX fraction, and Phs primarily included phenol and cresols, in agreement with previously reported results [47]. The bimetal Ni-Mo (experiment DO2) gave rise to high AHs yield and BTX selectivity, i.e. 33 wt. $\%$ and 83.7 wt. $\%$ respectively; with only 2.8 wt. $\%$ of the liquid products being Phs. The combination Ni-Fe (experiment DO6) led to both the lowest AHs yield and BTX yield and selectivity $(27.4,24.3$ and 70.3 wt.\% respectively). On the contrary, the highest Phs yield of 7.1 wt. $\%$, mainly 
227 composed of phenol, was obtained from DO6. The bimetal Mo-Fe yielded the highest 228 amount of AHs (33.9 wt.\%). However, it showed a BTX selectivity of 78.9 wt.\%, lower 229 than that obtained over Ni-Mo. 
230 Table 1 Conversion, product recovery and product yields (in wt. $\%$ of reactant) from anisole decomposition $\mathrm{x} \% \mathrm{M}-\mathrm{y} \% \mathrm{~N} / \mathrm{HZ}(25)$.

\begin{tabular}{|c|c|c|c|c|c|c|c|c|c|c|c|}
\hline \multirow{3}{*}{ No. } & \multirow{3}{*}{$\begin{array}{l}\text { Bimetal } \\
\text { /HZ(25) }\end{array}$} & \multirow{3}{*}{$\mathrm{T}\left({ }^{\circ} \mathrm{C}\right)$} & \multirow{3}{*}{$\begin{array}{c}\text { Conversion } \\
\text { (\%) }\end{array}$} & \multirow{3}{*}{$\begin{array}{l}\text { Product recovery } \\
\qquad \text { (\%) }\end{array}$} & \multicolumn{5}{|c|}{ Liquid products } & \multirow{3}{*}{ Gas yield } & \multirow{3}{*}{ Solid yield } \\
\hline & & & & & \multicolumn{4}{|c|}{ Liquid yield } & \multirow{2}{*}{ BTX selectivity $(\%)^{\mathrm{a}}$} & & \\
\hline & & & & & Total & Phs & AHs & BTX ${ }^{d}$ & & & \\
\hline $\mathrm{T} 2^{\mathrm{b}}$ & $\mathrm{HZ}(25)$ & 500 & 100.0 & n.d. & 41.2 & 10.0 & 31.2 & 23.6 & 57.1 & n.d. & 42.0 \\
\hline $\mathrm{D} 2^{\mathrm{b}}$ & $1 \% \mathrm{Ni}$ & 500 & 100.0 & 99.4 & 31.3 & 2.4 & 28.8 & 25.6 & 81.9 & 0.2 & 68.0 \\
\hline $\mathrm{D} 7^{\mathrm{b}}$ & $1 \% \mathrm{Mo}$ & 500 & 100.0 & 100.0 & 38.8 & 3.6 & 35.2 & 30.0 & 77.4 & 0.5 & 60.7 \\
\hline DO1 & & 400 & 99.6 & 100.0 & $38.8^{c}$ & 32.7 & 5.8 & 4.7 & 12.3 & 0.0 & 61.1 \\
\hline DO2 & $1 \% \mathrm{Ni}-1 \% \mathrm{Mo}$ & 500 & & 99.8 & 35.8 & 2.8 & 33.0 & 30.0 & 83.7 & 0.1 & 63.9 \\
\hline DO3 & & 600 & & 98.0 & 21.0 & 0.0 & 21.0 & 20.5 & 97.5 & 0.3 & 76.7 \\
\hline DO4 & $1 \% \mathrm{Ni}-0.5 \% \mathrm{Mo}$ & 500 & & 97.7 & 31.6 & 2.8 & 28.8 & 25.4 & 80.3 & 0.1 & 66.0 \\
\hline DO5 & $0.5 \% \mathrm{Ni}-1 \% \mathrm{Mo}$ & 500 & & 100.3 & 33.5 & 3.6 & 29.9 & 26.0 & 77.6 & 0.1 & 66.7 \\
\hline DO6 & $1 \% \mathrm{Ni}-1 \% \mathrm{Fe}$ & 500 & & 97.6 & 34.5 & 7.1 & 27.4 & 24.3 & 70.3 & 0.3 & 62.8 \\
\hline DO7 & $1 \% \mathrm{Mo}-1 \% \mathrm{Fe}$ & 500 & & 100.0 & 38.7 & 4.7 & 33.9 & 30.5 & 78.9 & 0.4 & 61.0 \\
\hline
\end{tabular}

a Selectivity calculated with respect to the total liquid yield, included unreacted anisole; ${ }^{\mathrm{b}}$ data is derived from reference [10,32]; ${ }^{\mathrm{c}}$ The value considers unreacted anisole. ${ }^{d}$ The individual selectivity of benzene, toluene and xylene of the experiments in this study is specified in Supplementary Material S3. 
234 Our research group has recently reported the conversion of anisole over non-metal 235 HZSM-5 zeolite [10]. Compared to the results previously reported, both the yield and selectivity of BTX have been enhanced by the addition of the bimetallic sites (on average by $20 \%$ and $36 \%$ respectively) $[10,32]$. The improvement is attributed to an 238 increment in the conversion of Phs towards BTX, and indicates that the studied 239 supported bimetallic catalysts may promote the deoxygenation of Phs. Our research 240 group has also investigated the anisole decomposition over single metal loaded HZSM2415 [32]. In that work, $1 \% \mathrm{Ni} / \mathrm{HZ}(25)$ was observed to give rise to very high $\mathrm{BTX}$ selectivity $242(81.9 \%)$, while $1 \% \mathrm{Mo} / \mathrm{HZ}(25)$ gave rise to higher yield of $\mathrm{BTX}$ yield $(30.0 \mathrm{wt} \%)$ but 243 lower selectivity $(77.4 \%)$. When comparing to the liquid product yields obtained over $2441 \% \mathrm{Ni}-1 \% \mathrm{Mo} / \mathrm{HZ}(25)$, it is observed that the bimetallic catalyst seemed to retain both 245 the high BTX yield achieved over $1 \% \mathrm{Mo} / \mathrm{HZ}(25)$, and the high BTX selectivity obtained 246 from $1 \% \mathrm{Ni} / \mathrm{HZ}(25)$. The improvement in the yield and selectivity of BTX is related to the 247 lower formation of carbonaceous deposit compared to the case of $1 \% \mathrm{Ni} / \mathrm{HZ}(25)(63.9$ 248 wt. \% vs. 68.0 wt.\%), and the lower PAH yield compared to the case of $1 \% \mathrm{Mo} / \mathrm{HZ}(25)$ 249 (3.05 wt.\% vs. 5.22 wt.\%). This result confirms the hypothesis that the combination of $250 \mathrm{Ni}$ and Mo active sites as a $\mathrm{HZ}(25)$ supported bimetallic catalyst promotes a synergetic 251 effect on the catalytic activity for the deoxygenation stage of the decomposition of 252 anisole. 


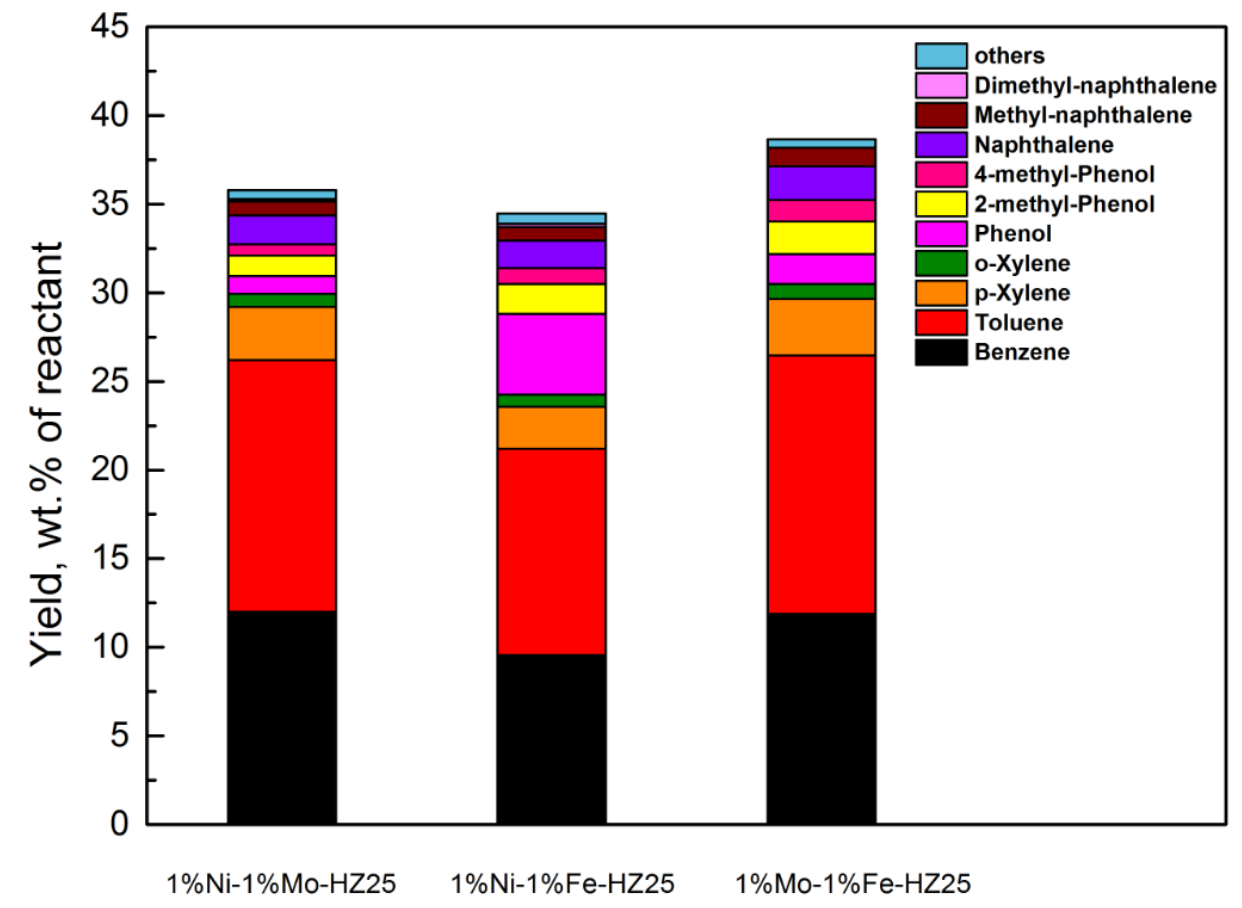

254 Fig. 1 Influence of the type of bimetal/ $\mathrm{HZ}(25)$ catalysts on the liquid product yields obtained from anisole decomposition. Reaction temperature $=500^{\circ} \mathrm{C}$

256 Compared to $1 \% \mathrm{Ni} / \mathrm{HZ}(25)$ [32], the combination of $1 \% \mathrm{Ni}-1 \% \mathrm{Fe} / \mathrm{HZ}(25)$ resulted in a 257 decrease in carbonaceous deposits. This result implies that Fe may moderate the 258 deactivation of the catalyst by alleviate the polycondensation reactions over catalyst 259 surface [48]. However, the BTX yield and selectivity were also reduced because of the 260 lower conversion of Phs. Compared to $1 \% \mathrm{Mo} / \mathrm{HZ}(25)$ [32], the combination of $1 \% \mathrm{Mo}-$ $2611 \% \mathrm{Fe} / \mathrm{HZ}(25)$ showed negligible impact on BTX yield and carbonaceous deposit yield, 262 and a slight increase in BTX selectivity. The results suggest that the addition of Fe sites 263 to the catalyst restrict the catalytic activity of $\mathrm{Ni}$ site and have almost no improvement 264 on the catalytic activity of Mo sites. Therefore, among the three bimetallic catalyst 265 supported on zeolite, $1 \% \mathrm{Ni}-1 \% \mathrm{Mo}$ exhibited better catalytic activity towards the 266 production of BTX, giving rise to both higher yield and selectivity. Consequently, this 267 bimetallic catalyst was selected for further investigation of the effect of temperature and metal loadings. 


\subsection{Effect of temperature on deoxygenation reaction over bimetal/HZ(25)} catalysts

271 Anisole decomposition over the $1 \% \mathrm{Ni}-1 \% \mathrm{Mo} / \mathrm{HZ}(25)$ catalyst was performed at 400 , 272500 , and $600{ }^{\circ} \mathrm{C}$ (DO1, DO2, and DO3 in Table 1, respectively) to investigate the effect 273 of temperature on the deoxygenation stage. Total conversion of anisole was achieved 274 at all temperatures, with the liquid and carbonaceous deposits being the main products 275 at this temperature range. The total liquid product yield decreased significantly with temperature from $38.4 \mathrm{wt} . \%$ (excluding undecomposed anisole) at $400^{\circ} \mathrm{C}$ to $21.0 \mathrm{wt} . \%$ 277 at $600^{\circ} \mathrm{C}$. On the contrary, the yield of carbonaceous deposits increased correspondingly from $61.1 \mathrm{wt} . \%$ at $400^{\circ} \mathrm{C}$ to $76.7 \mathrm{wt} . \%$ at $600^{\circ} \mathrm{C}$. Trace gas products were produced (further details are shown in Supplementary Material S8).

280 The change in the liquid product distribution with temperature is shown in Fig. 2. At $400^{\circ} \mathrm{C}$, Phs were the main compounds in the liquid fraction; they accounted for 32.7 wt.\% of the total products and consisted mainly of phenol, ortho-cresol and para-cresol. The AHs fraction only constituted $5.8 \mathrm{wt} . \%$ of the total products, and mainly contained BTX (over 80 wt.\% of the AHs), and naphthalene and its derivatives. On the contrary, the Phs yield was $2.8 \mathrm{wt} . \%$ and the AHs yield was $33.0 \mathrm{wt} . \%$ of the total product at $500^{\circ} \mathrm{C}$. The liquid fraction contained $83.7 \%$ of BTX. At $600^{\circ} \mathrm{C}$, no Phs were detected, and the AHs yield was $21.0 \mathrm{wt} \%$. Despite the decrease in the total AHs fraction compared to that at $500^{\circ} \mathrm{C}$, the BTX fraction increased up to a selectivity of $97.5 \%$, with benzene being the main product. The results point that the transmethylation reaction primarily occurred at $400^{\circ} \mathrm{C}$, and the deoxygenation reaction occurred at $500^{\circ} \mathrm{C}$ and higher. This confirms that the "transition temperature"( at which the transition from prevalence of transmethylation to prevalence of deoxygenation happens) in the decomposition of anisole over the bimetallic based catalysts is the same as that 

catalysts.

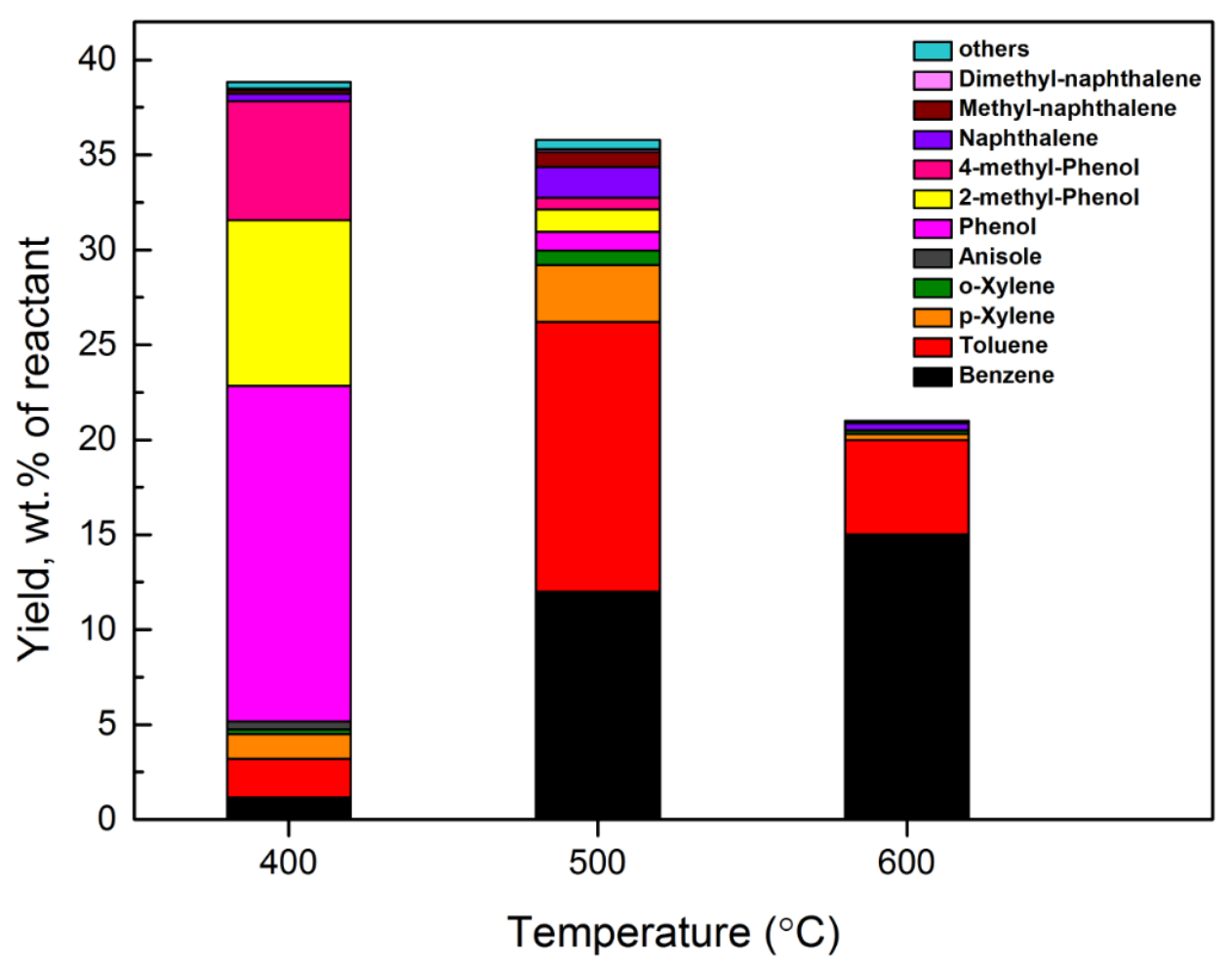

Fig. 2 Influence of temperature on the liquid product yields obtained from anisole decomposition over $1 \% \mathrm{Ni}-1 \% \mathrm{Mo} / \mathrm{HZ}(25)$

The results in Table 1 show that an increase in temperature from $400^{\circ} \mathrm{C}$ to $600^{\circ} \mathrm{C}$ enhanced carbonaceous deposition, with a simultaneous reduction in the liquid products. The effect of temperature on the distribution of liquid products is also noticeable, as shown in Fig. 2. The increase in temperature from 400 to $500^{\circ} \mathrm{C}$ resulted in a rapid decrease of Phs, since they are intermediate compounds in the anisole decomposition and are consumed by deoxygenation and polycondensation reactions at higher temperatures $[29,32]$. Indeed, no Phs were detected at $600^{\circ} \mathrm{C}$. Similar results were obtained over single metal catalyst supported on zeolite and reported by our 307 research group [32]. From 500 to $600^{\circ} \mathrm{C}$, a preferential decrease in polycyclic aromatic hydrocarbons (PAHs) was observed, simultaneously contributing to a decrease of the 
309 AHs yield of around 12 wt.\% and an increase in BTX selectivity of approximately $14 \%$.

310 These results suggest that, at higher temperatures, PAHs were involved in 311 polycondensation reactions to form carbonaceous deposits [32]. The occurrence of

312 these polycondensation reactions resulted in more than $76 \mathrm{wt} \%$ of carbonaceous

313 deposit at expense of the liquid yield, while simultaneously releasing hydrogen.

314 Considering the BTX yield and selectivity values obtained at different temperatures

315 over $1 \% \mathrm{Ni}-1 \% \mathrm{Mo} / \mathrm{HZ}(25)$, the temperature of $500^{\circ} \mathrm{C}$ is a regarded as a fair compromise 316 for optimum operating temperature as high Phs conversion is achieved while 317 polycondensation is moderate.

\subsection{Effect of metal loading on deoxygenation reaction over bimetal/HZ(25)} catalysts

Experiments of anisole decomposition over the catalysts of $1 \% \mathrm{Ni}-1 \% \mathrm{Mo} / \mathrm{HZ}(25)$ (DO2), $1 \% \mathrm{Ni}-0.5 \% \mathrm{Mo} / \mathrm{HZ} / 25(\mathrm{DO} 4)$ and $0.5 \mathrm{Ni}-1 \% \mathrm{Mo} / \mathrm{HZ}(25)(\mathrm{DO} 5)$ at $500^{\circ} \mathrm{C}$ to investigate the effect of metal loading ratio on the deoxygenation reaction. As shown in Table 1, anisole was completely converted in all the cases, and rather similar product yields were obtained over the three catalysts (from 63.9 wt. $\%$ to 66.7 wt. $\%$ for carbonaceous deposits, and from 31.6 wt. $\%$ to 35.8 wt. \% for liquid products). Gaseous products were negligible (as shown in Supplementary Material S8). The influence of the metal loading on the liquid product distribution is depicted in Fig. 3.

The composition of liquid fraction exhibited little variation for the three experiments, and mainly consisted of BTX, phenol, cresols, naphthalene, methyl naphthalene and trace of phenanthrene. The highest yields of $\mathrm{AHs}$ and $\mathrm{BTX}$ were obtained over $1 \% \mathrm{Ni}$ $1 \% \mathrm{Mo} / \mathrm{HZ}(25)$ (experiment DO2). The decrease in the Mo loading from 1 to $0.5 \mathrm{wt} . \%$

332 (experiment DO4) resulted in the decrease of around $4.5 \mathrm{wt} \%$ for both AHs and BTX yields, while no change was observed in the yield of Phs. It was also observed that 
334 BTX selectivity only had a slight decrease when the Mo loading was reduced. This 335 implies that a loading of 0.5 wt.\% Mo may still exhibit good synergistic effect with $\mathrm{Ni}$ 336 active sites in assisting promoting the formation of BTX products, as discussed in 337 Section 3.2. Negligible change of carbonaceous deposit yield was observed, indicating polycondensation reactions is not sensitive to change of the loading of Mo. The results agree reported conclusion that the ability of Mo active sites hinder polycondensation reactions and prevent further reaction of liquid products especially AHs [32].

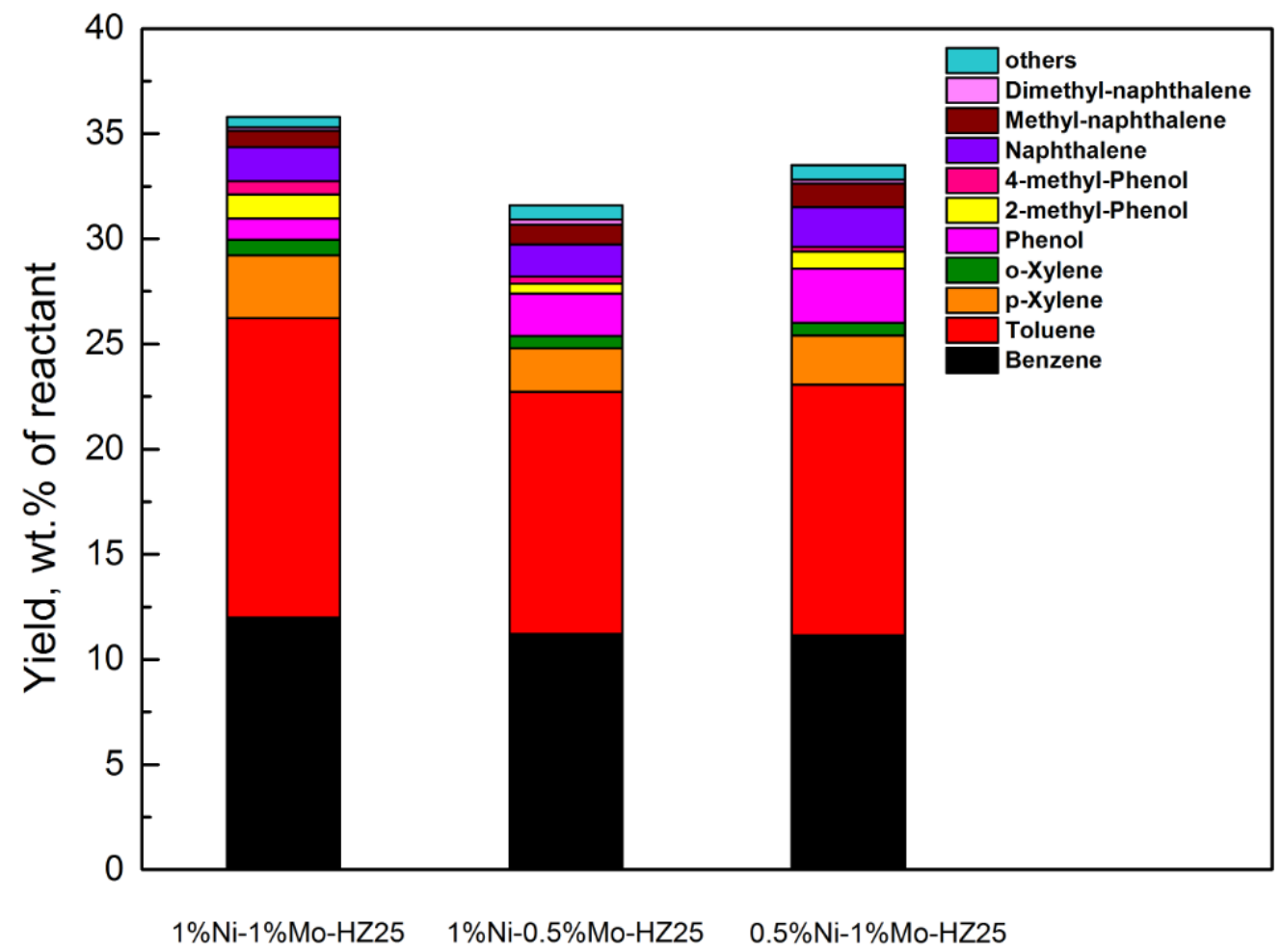

Fig. 3 Influence of metal loading on the liquid product yields obtained from deoxygenation reaction over $\mathrm{x} \% \mathrm{Ni}-\mathrm{y} \% \mathrm{Mo} / \mathrm{HZ}(25)$ catalysts. Reaction temperature $=$ $500^{\circ} \mathrm{C}$

345 The decrease in the Ni loading from 1.0 to $0.5 \mathrm{wt} \%$ (experiments DO2 and DO5, respectively) gave rise to a reduction in the yield of $\mathrm{AHs}$ of around $3.0 \mathrm{wt} . \%$, and in the 347 yield and selectivity of BTX of around 4.0 wt. $\%$ and 6.0 wt.\% respectively. The 348 decrease in AHs and particularly BTX fraction is related to the increase in the yields of 
both Phs and PAH compounds. The results reflect the key role of Ni sites in promoting

350 BTX selectivity by converting more Phs to mono AHs in the deoxygenation reactions.

351 The change in BTX yield when reducing the amount of Ni (i.e. DO5 vs. DO2 results)

352 also supports the argument of the synergistic effect of $\mathrm{Ni}$ in assisting Mo to promote the

353 yield of BTX. When comparing the products obtained over $0.5 \% \mathrm{Ni}-1 \% \mathrm{Mo} / \mathrm{HZ}(25)$ and

$3541 \% \mathrm{Mo} / \mathrm{HZ}(25)[32]$, it can be observed that the addition of $0.5 \% \mathrm{Ni}$ preserved the BTX

355 selectivity despite the yields of AHs and BTX decreased in favour of more

356 carbonaceous deposits. The results indicate that the addition of $0.5 \mathrm{wt} \% \mathrm{Ni}$ to

$3571 \% \mathrm{Mo} / \mathrm{HZ}(25)$ was observed to be actually detrimental to the performance of the

358 catalyst because polycondensation is promoted. The addition of $1.0 \mathrm{wt} \% \mathrm{Ni}$ to

$3591 \% \mathrm{Mo} / \mathrm{HZ}(25)$ promoted the BTX selectivity despite the fact that the amount of

360 carbonaceous deposit also increase. The results suggest that the selection of the

$361 \mathrm{Ni} /$ Mo loading ratio of the catalyst is not trivial, and it determines the synergetic effect

362 between both active metals.

\section{$363 \quad 3.4$ Characterization of fresh and spent catalysts}

364 Fresh catalysts were analysed by TEM-EDS to evaluate the surface morphology of the active metals. The catalysts $1 \% \mathrm{Ni}-1 \% \mathrm{Mo} / \mathrm{HZ}(25), 1 \% \mathrm{Ni}-1 \% \mathrm{Fe} / \mathrm{HZ}(25)$, and $1 \% \mathrm{Mo}-$ $1 \% \mathrm{Fe} / \mathrm{HZ}(25)$ were observed at four resolutions $(500 \mathrm{~nm}, 100 \mathrm{~nm}, 50 \mathrm{~nm}$ and $20 \mathrm{~nm})$. In addition, the spent $1 \% \mathrm{Ni}-1 \% \mathrm{Mo} / \mathrm{HZ}(25)$ catalyst from experiment $\mathrm{DO} 2$ was analysed to characterize the carbonaceous deposits on the surface.

369 Representative TEM micrographs of the fresh catalyst are shown in Fig. 4 (a), (b) and

370 (c), and Supplementary Material S4 to S6 respectively. In all cases, the bimetal active

371 sites were found to be highly dispersed on the zeolite surface and in the form of 372 microcrystals, as pointed by the SAED patterns shown in the Supplementary Material 373 S4 to S6 [49,50]. The bimetallic particles showed diameters around $10 \mathrm{~nm}$, in line with what literature reported [35], although the individual particles were difficult to 
375 distinguish due to the unclear boundaries. In addition, giant particles (over $20 \mathrm{~nm}$ ) were

376 observed in the fresh catalysts of Ni-Mo and Ni-Fe loaded $\mathrm{HZ}(25)$ as shown in Fig. 4,

377 whose formation is attributed to the likely occurrence of bimetal agglomeration caused

378 by the high adsorption ability of Ni during the catalyst reduction [51].

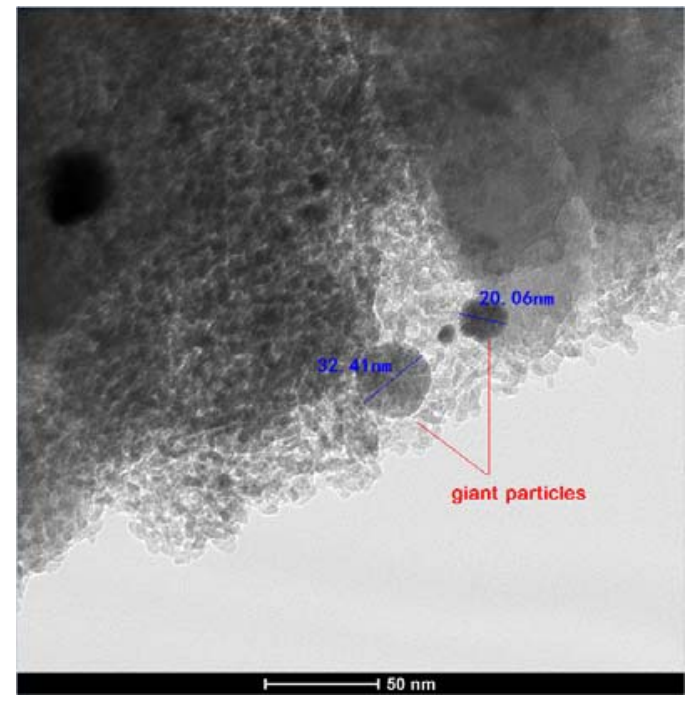

(a)

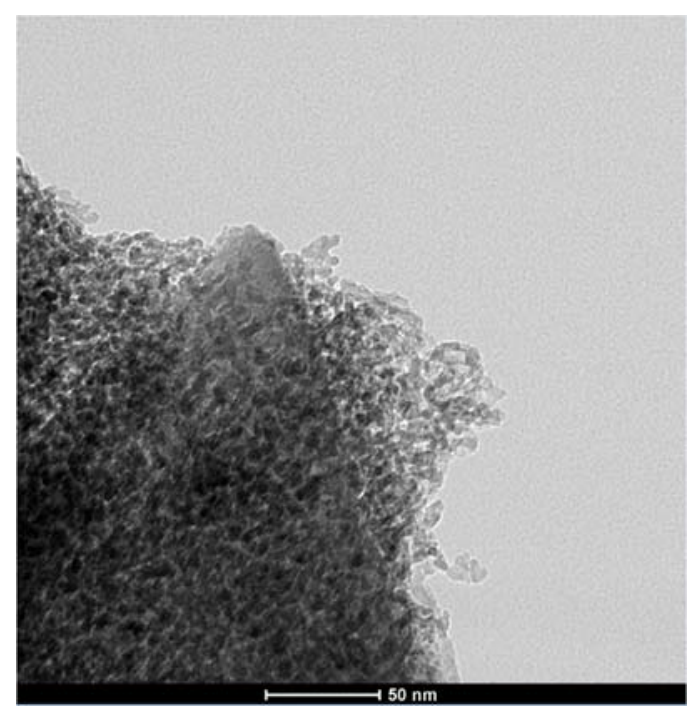

(c)

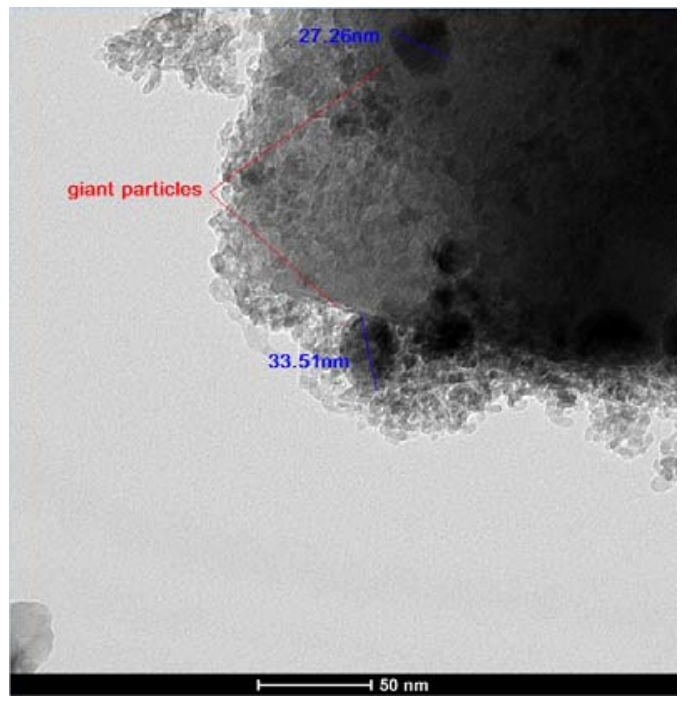

(b)

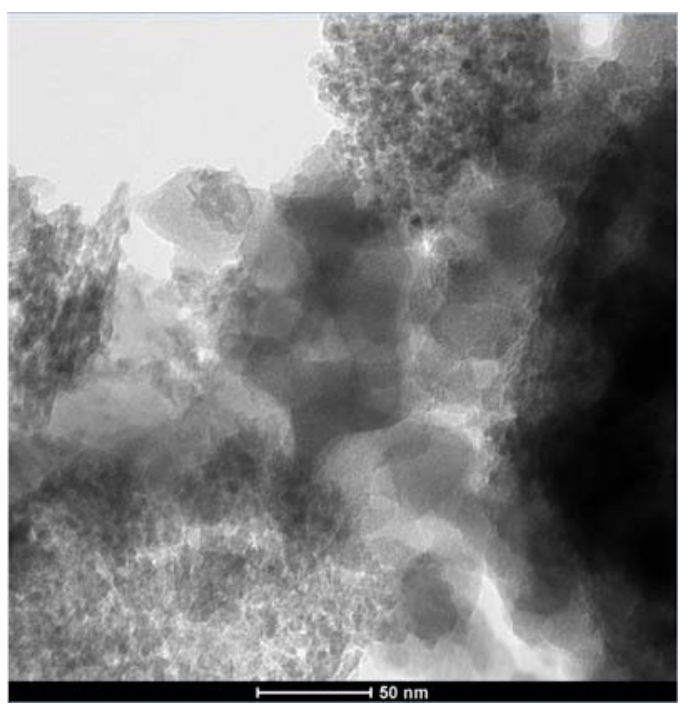

(d) 

$1 \% \mathrm{Fe} / \mathrm{HZ}(25)$, (c) $1 \% \mathrm{Mo}-1 \% \mathrm{Fe} / \mathrm{HZ}(25)$; and (d) the spent catalysts $1 \% \mathrm{Ni}-1 \% \mathrm{Mo} / \mathrm{HZ}(25)$ after experiment DO2

382 Representative TEM micrograph of the spent $1 \% \mathrm{Ni}-1 \% \mathrm{Mo} / \mathrm{HZ}(25)$ catalyst is shown in 383 Fig. 4 (d), and Supplementary Material S9. Cloud-shaped carbonaceous deposits were 384 observed, covering the metal particles to the point that they were almost non-visible. 385 Nevertheless, no further agglomeration of particles was observed compared to the fresh catalyst. The carbonaceous deposits exhibited amorphous nature, also confirmed by the absence of diffraction circles in the Fast Fourier Transform (FFT) image (provided in Supplementary Material S9).

The surface of the three fresh catalysts and the spent catalysts were analysed by EDS tests in order to identify and quantify the main elements present in the surface, as shown in Table 2 and Supplementary Material S7 and S10. For each of the fresh catalysts, the active metal species were found to be in a concentration around $1 \mathrm{wt} . \%$ (based on the whole catalyst sample), in close agreement with the designed loading ratio. In the case of the spent catalyst, carbon element accounting for around $10 \mathrm{wt} \%$ of the unit catalyst sample. In the case of the identified oxygen element, it should be noticed that oxygen could be both present in the carbonaceous deposit and be part of the zeolite structure oxygen, but the technique is not able to distinguish between them. The results of TEM-EDS showed that most of the surface area of the spent bimetallicbased catalyst was covered by amorphous carbonaceous deposits.

400 Table 2 EDS surface characterisation of fresh and spent bimetallic catalyst supported 401 on $\mathrm{HZ}(25)$

\begin{tabular}{|c|c|c|c|}
\hline \multicolumn{3}{|c|}{ Fresh Catalyst (/HZ(25)) } & \multirow{2}{*}{$\begin{array}{l}\text { Spent Catalyst } / \mathrm{HZ}(25) \\
1 \% \mathrm{Ni}-1 \% \mathrm{Mo}\end{array}$} \\
\hline $1 \% \mathrm{Ni}-1 \% \mathrm{Mo}$ & $1 \% \mathrm{Ni}-1 \% \mathrm{Fe}$ & $1 \% \mathrm{Mo}-1 \% \mathrm{Fe}$ & \\
\hline
\end{tabular}




\begin{tabular}{lllllllll}
\hline Ele & wt.\% & Atomic\% & wt.\% & Atomic\% & wt.\% & Atomic\% & wt.\% & Atomic $\%$ \\
\hline $\mathrm{Ni}$ & 1.1 & 0.4 & 1.3 & 0.5 & - & - & 0.6 & 0.2 \\
$\mathrm{Mo}$ & 1.0 & 0.2 & - & - & 0.8 & 0.2 & 1.0 & 0.2 \\
$\mathrm{Fe}$ & - & - & 1.4 & 0.5 & 1.3 & 0.5 & - & - \\
$\mathrm{C}$ & - & - & - & - & - & - & 10.2 & 15.9 \\
$\mathrm{O}$ & - & - & - & - & - & - & 48.1 & 56.5 \\
\hline
\end{tabular}

402 To further evaluate the separate performance of each metal active site in the optimal 403 catalyst, the life of each active sites in the catalyst of $\mathrm{Ni}-\mathrm{Mo} / \mathrm{HZ}(25)$ was assessed by 404 the conversion of anisole over $\mathrm{Ni}$ active site $(\mathrm{Ni} / \mathrm{HZ}(25))$ and Mo active site $(\mathrm{Mo} / \mathrm{HZ}(25))$ 405 respectively in a time range of 100 minutes. Results showed that both active sites were 406 stable during the decomposition of anisole, and the conversion over both active sites 407 remained over $85 \%$ after the $100 \mathrm{~min}$ reaction. Details are shown in Supplementary 408 Material S11.

3.5 DFT modelling of anisole and phenol onto the surface of bimetal crystals

411 To further elucidate the findings from experiments, the interaction and adsorption 412 energy of anisole and phenol, reactant molecules during the anisole decomposition 413 process, onto bimetal crystals were analysed by means of DFT modelling.

414 The adsorption energy for anisole and phenol adsorption onto each bimetal surface is 415 shown in Table 3. The highest adsorption energy for both anisole and phenol 416 molecules was observed in the case of $\mathrm{Ni}-\mathrm{Mo}$ alloy, in accord with the highest 417 production of Ni-Mo bimetal loading shown in the experiments. The adsorption energy 418 values were lower for those alloys containing Fe, and Ni-Fe surface showed the lowest 419 adsorption energy for both adsorbates. This agrees with the experimental results that $420 \mathrm{Ni}-\mathrm{Fe}$ and Mo-Fe contained catalysts may moderate the deactivation of the catalyst by 
421 weakening the high adsorption capability of Ni-Mo loading. The difference in the 422 adsorption energy values between $\mathrm{Ni}-\mathrm{Fe}$ and Mo-Fe agrees with the lower adsorption 423 energy previously observed for anisole adsorption on $\mathrm{Ni}$ compared to anisole 424 adsorption on Mo [33].

425 Table 3 Adsorption energy of anisole and phenol onto the bimetal surfaces

\begin{tabular}{ccc}
\hline & \multicolumn{2}{c}{ Adsorption energy $(\mathrm{kcal} / \mathrm{mol})$} \\
\cline { 2 - 3 } Bimetal Surface & Anisole & Phenol \\
\hline Ni-Mo & 72.67 & 79.88 \\
Ni-Fe & 43.08 & 45.41 \\
Mo-Fe & 63.99 & 60.67
\end{tabular}

426 The interaction between the alloy adsorbent and the phenol as model adsorbate was 427 further evaluated by the analysis of the electron distribution vibration in the phenol 428 molecule, as shown in Fig. 5, Fig. 6 and Fig. 7. As the catalytic performance of the 429 bimetallic sites on the deoxygenation reactions highly depends on their ability to disturb 430 the oxygen in the phenolic molecules [52-54], the contribution of oxygen to the overall 431 Density of States (DOS) change in the phenol molecule was also determined. 432 Electrons in s, p, d orbitals were considered for these cases.
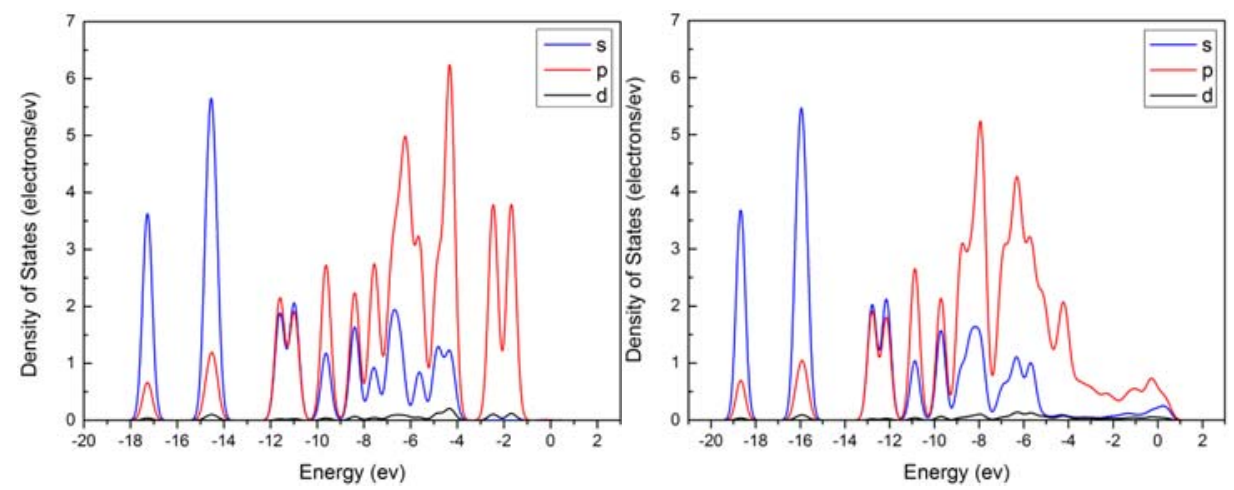
(a)

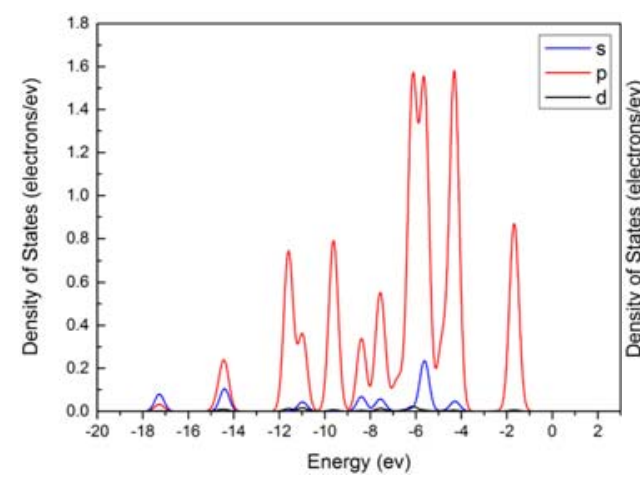

(c) (b)

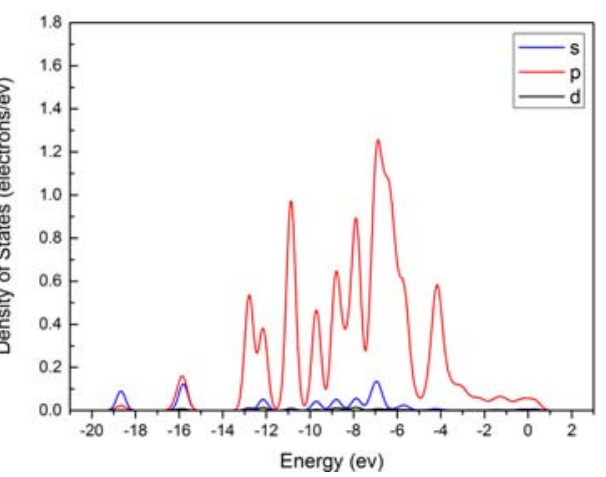

(d)

437

Fig. 5 Density of States (DOS) of Phenol: (a) approaching to Ni-Mo; (b) adsorbed on

438

Ni-Mo. Oxygen contribution to DOS, Partial DOS (PDOS): (c) approaching to Ni-Mo; (d)

439 adsorbed on Ni-Mo.

440

441

442

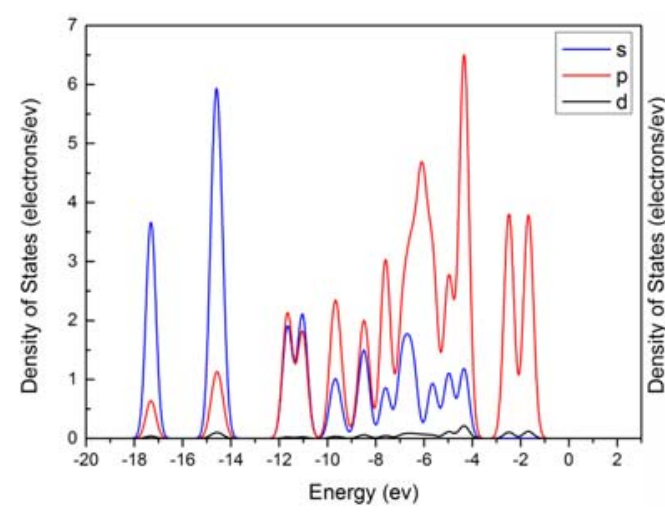

(a)

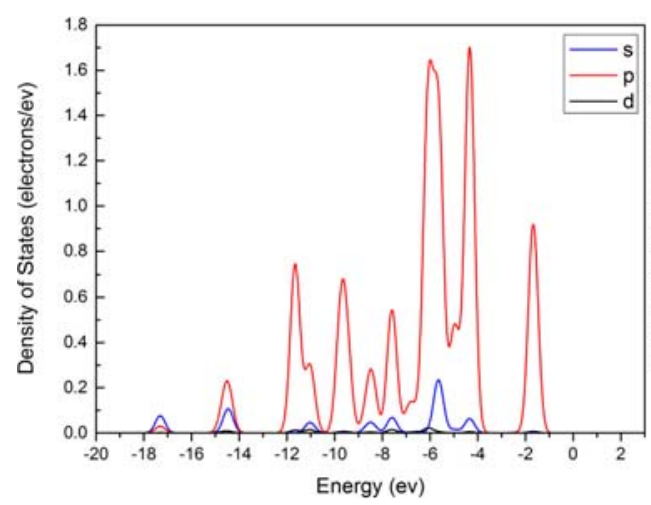

(c)

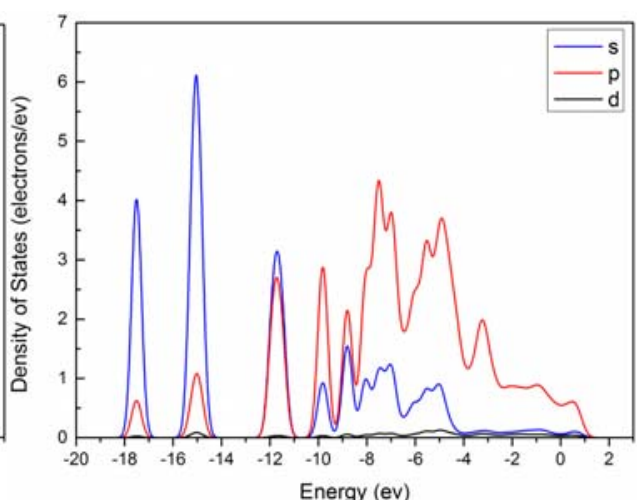

(b)

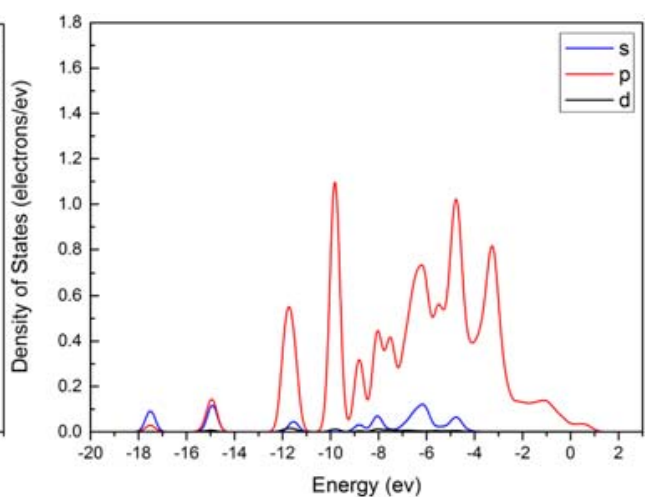

(d) 
Fig. 6 Density of States (DOS) of Phenol: (a) approaching to Ni-Fe; (b) adsorbed on Niadsorbed on Ni-Fe.

447

448

449

450

451

452

453

454

455

456

457

458

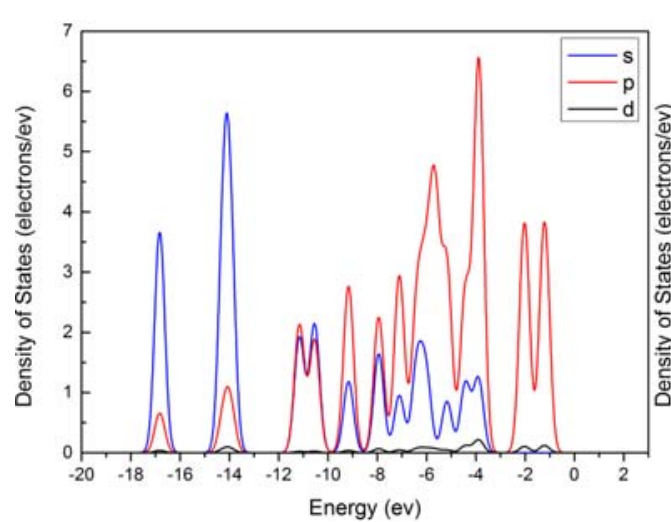

(a)

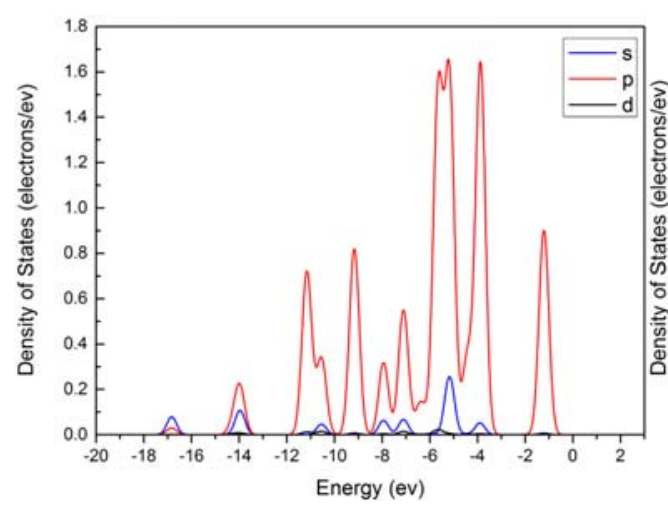

(c)

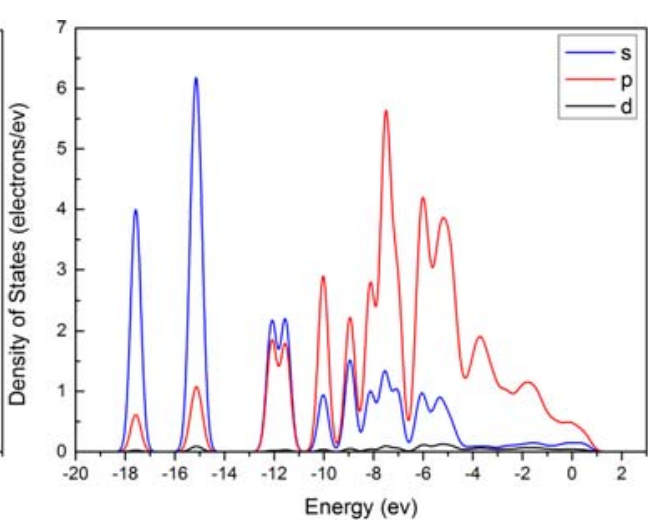

(b)

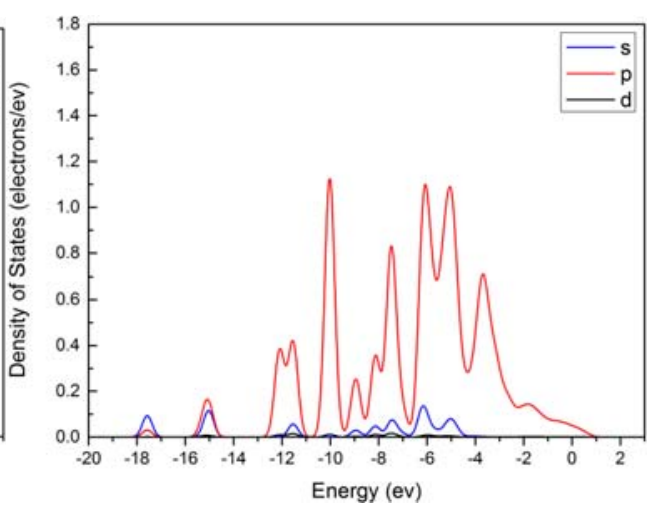

(d)

Fig. 7 Density of States (DOS) of Phenol: (a) approaching to Mo-Fe; (b) adsorbed on Mo-Fe. Oxygen contribution to DOS, Partial DOS (PDOS): (c) approaching to Mo-Fe; (d) adsorbed on Mo-Fe.

Phenol molecule exhibited similar DOS profiles when approaching to (distance above 5 A) the three alloys (plot (a) in Fig. 5, Fig. 6 and Fig. 7). Nevertheless, the energy level of the electrons in the phenol molecule was $0.5 \mathrm{eV}$ higher when approaching to Mo-Fe alloy compared to Ni-Mo and Ni-Fe alloys. This result indicates that the types of metals in the alloy had little impact on the phenol molecule before the adsorption took place, 
when the distance between adsorbate and adsorbent was larger than $5 \AA$. It can be 460 observed from the spectra before the adsorption that the electrons in s orbital of the 461 phenol molecule were primarily located at low energy levels (between -18 and $-10 \mathrm{eV}$ ),

462 while higher energy levels (between -12 and $-1 \mathrm{eV}$ ) were occupied by $\mathrm{p}$ electrons. Nevertheless, it is worth noting that some s orbital electrons were also present in higher energy levels (between -10 to $-4 \mathrm{eV}$ ), indicating the hybridization of orbitals within the phenol molecule. Once phenol molecule was adsorbed onto the bimetal surfaces (as shown in plot (b) in Fig. 5, Fig. 6 and Fig. 7), the DOS spectra for both the $s$ and $p$ electrons showed displacement of energy levels and changes in value of states, particularly at energy levels higher than $-10 \mathrm{eV}$. These changes varied depending on the alloy. In the case of the phenol adsorbed on Ni-Mo alloy, the energy level of most electrons in $\mathrm{s}$ and $\mathrm{p}$ orbitals decreased about $1.5 \mathrm{eV}$. This relates to the contribution to the energy released by the whole system during the adsorption process, which is an exothermic process. The change in energy also reveals a more stable structure of the molecule compared to that prior to adsorption. In the case of $\mathrm{Ni}-\mathrm{Mo}$, the value of DOS changed especially at the energy levels above $-4 \mathrm{eV}$; electrons were gained from $\mathrm{Ni}-$ Mo alloy at some of the energy levels during the adsorption process. This is related to the electron exchange between the phenol molecule and the adsorbent surface, and confirms the chemisorption between the phenol molecule and Ni-Mo alloy [55]. Similar change of DOS values was observed for the adsorption of phenol onto $\mathrm{Ni}-\mathrm{Fe}$ and MoFe alloys. However, the displacement of the energy levels for each orbital was lower compared to the adsorption on Ni-Mo. this agrees with the results that Fe contained alloys led to lower adsorption energy compared to Ni-Mo. In the case of Ni-Fe surface, the adsorbed phenol molecule showed a small displacement of energy level but more gained electrons, mainly in $\mathrm{p}$ orbital at energy levels above $-2 \mathrm{eV}$. This result agrees with the predicted lowest adsorption energy for Ni-Fe and shown in Table 3. At the same time, it implies that Fe had more significant electron back-donation transfer to the 
absorbed phenol molecule, which may give rise to strong interaction between $\mathrm{Ni}-\mathrm{Fe}$

487 alloy surface and the adsorbate molecule [55]. Larger displacement of energy level of 488 the orbital electrons was observed in the case of Mo-Fe compared to Ni-Fe. This result 489 points that Mo led to higher adsorption energy than $\mathrm{Ni}$ [33]. The increased density of $p$ orbital electrons at high energy levels also confirms that Fe effectively interacted with the adsorbate by electron transfer.

Plots (c) and (d) in Fig. 5, Fig. 6 and Fig. 7 show the Partial DOS (PDOS) of the oxygen atom in the phenol molecule before and after adsorption onto each alloy. The PDOS spectra of the oxygen were similar regardless the difference in alloy composition. In the three cases, it was found that most electrons in s orbital were located at high energy levels ranged from -9 to $-3 \mathrm{eV}$, hybridized with $\mathrm{p}$ electrons. After adsorption, the energy of frontier orbitals of the oxygen atom in the case of the Ni-Mo system showed the largest decrease in the energy level $(>1 \mathrm{eV})$. Simultaneously, a slight decrease of magnitude of the DOS values at most of the energy levels except an increase of the values mainly at high energy levels above $-4 \mathrm{eV}$ were observed. The changes of DOS values were more significant for $\mathrm{Ni}-\mathrm{Fe}$ and Mo-Fe. These results indicate the strong impact of the metallic surfaces on the electron distribution of the oxygen atom. It is inferred that the changes in $p$ electrons may include the two non-hybridized $2 p$ orbital electrons of oxygen atom that engage in $\pi-p$ conjugation; consequently making the hydroxyl group more reactive and favouring the deoxygenation reactions. of the phenol molecule, and the influence of the type of metals in the alloy is similar to both the phenol molecule and the oxygen atom. $\mathrm{Ni}$ and Mo generate stronger binding with the adsorbate molecule by releasing more energy during the adsorption, while Fe

510 gives rise to more electron exchange between the metallic surface and the adsorbate $511 \quad[55]$. 
512 Although the three bimetal surfaces show strong interaction with the reactant

513 molecules, the stronger binding exhibited by the Ni-Mo surface could benefit more the

514 deoxygenation reaction in the decomposition of anisole in promoting the yield and

515 selectivity towards desirable products based on the experimental results.

\section{4. Conclusion}

517 In this work, experiments of anisole decomposition were carried out over bi-metals 518 loaded $\mathrm{HZ}(25)$. The experimental results showed that Ni-Mo could combine the positive

519 effects of respective $\mathrm{Ni}$ and Mo by maintaining the high yield of BTX for $30 \mathrm{wt} \%$ while

520 promoting the its selectivity to $83.7 \%$. $1 \%$ was the optimal loading ratio for the bi-metal

521 synergistic effect. $500^{\circ} \mathrm{C}$ was found to be a compromise temperature for the BTX

522 production in the deoxygenation reactions, giving rise to high selectivity of BTX with 523 moderate polycondensation of both Phs and AHs. Fe showed negative effect as part of 524 the bi-metal in promoting the BTX yield and selectivity in the decomposition of anisole.

525 The TEM-EDS test to fresh catalysts confirmed the actual bi-metal loadings agreed 526 with the designed value, and showed the microcrystal particles of the bi-metal loadings 527 had fuzzy boundaries and readily agglomerated after the reduction. TEM-EDS test of 528 the spent $1 \% \mathrm{Ni}-\% \mathrm{Mo} / \mathrm{HZ}(25)$ showed evidence of amorphous carbon deposited after 529 the reaction. DFT modelling revealed that Ni-Mo alloy promoted the decline in electrons 530 energy levels and consequently exhibited the highest adsorption energy, while Fe was 531 more effective in back-donating electrons between the surface and the frontier orbitals 532 in the adsorbate. A stronger binding caused by Ni-Mo loading made it more efficient for 533 the deoxygenation during anisole decomposition, in line with the experimental results.

\section{Author information}

\section{Corresponding Authors}




\section{Author Contributions}

539 All authors have given approval to the final version of the manuscript.

$540 \quad$ Notes

541 The authors declare no competing financial interest.

\section{Acknowledgement}

543 The authors would like to acknowledge financial support from the National Natural

544 Science Foundation of China (project references: 51476034 and 51628601), Natural

545 Science Foundation of Jiangsu Province (project reference: BK20161423), the FP7

546 Marie Curie iComFluid (project reference: 312261), and the Leverhulme Trust

547 Research Grant (project reference: RPG-2017-254).

\section{References}

549 [1] Boerjan W, Ralph J, Baucher M. Lignin Biosynthesis. Annu Rev Plant Biol 2003;54:519-46. doi:10.1146/annurev.arplant.54.031902.134938.

551 [2] Lancefield CS, Westwood NJ. The synthesis and analysis of advanced lignin model polymers. Green Chem 2015;17:4980-90. doi:10.1039/C5GC01334H.

553 [3] Liu W-JJ, Jiang H, Yu H-QQ. Thermochemical conversion of lignin to functional 554 materials: a review and future directions. Green Chem 2015;17:4888-907. doi:10.1039/C5GC01054C.

556 [4] Bridgwater AV V. Review of fast pyrolysis of biomass and product upgrading. Biomass and Bioenergy 2012;38:68-94. doi:10.1016/j.biombioe.2011.01.048.

558 [5] Bridgwater AV V, Peacocke GVC. Fast pyrolysis processes for biomass. Renew 
560 [6] Jung KA, Woo SH, Lim S-R, Park JM. Pyrolytic production of phenolic compounds from the lignin residues of bioethanol processes. Chem Eng $\mathrm{J}$ 2015;259:107-16. doi:10.1016/j.cej.2014.07.126.

563

[7] Shen DK, Gu S, Luo KH, Wang SR, Fang MX. The pyrolytic degradation of 564 wood-derived lignin from pulping process. Bioresour Technol 2010;101:6136-46. doi:10.1016/j.biortech.2010.02.078.

[8] Hurff SJ, Klein MT. Reaction pathway analysis of thermal and catalytic lignin fragmentation by use of model compounds. Ind Eng Chem Fundam 1983;22:426-30. doi:10.1021/i100012a012.

[9] Zhu X, Mallinson RG, Resasco DE. Role of transalkylation reactions in the conversion of anisole over HZSM-5. Appl Catal A Gen 2010;379:172-81. doi:10.1016/j.apcata.2010.03.018.

572 [10] Zhang J, Fidalgo B, Shen D, Xiao R, Gu S. Mechanism of transmethylation in 573 574 anisole decomposition over HZSM-5: Experimental study. J Anal Appl Pyrolysis 2016;122:323-31. doi:10.1016/j.jaap.2016.09.009.

[11] Li X, Chen G, Liu C, Ma W, Yan B, Zhang J. Hydrodeoxygenation of lignin576 derived bio-oil using molecular sieves supported metal catalysts: A critical review. Renew Sustain Energy Rev 2017;71:296-308. doi:10.1016/j.rser.2016.12.057.

578 579

[12] Meng Q, Fan H, Liu H, Zhou H, He Z, Jiang Z, et al. Efficient Transformation of Anisole into Methylated Phenols over High-Silica HY Zeolites under Mild Conditions. ChemCatChem 2015;7:2831-5. doi:10.1002/cctc.201500479.

[13] Prasomsri T, To AT, Crossley S, Alvarez WE, Resasco DE. Catalytic conversion of anisole over HY and HZSM-5 zeolites in the presence of different hydrocarbon mixtures. Appl Catal B Environ 2011;106:204-11. doi:10.1016/j.apcatb.2011.05.026. 
585 [14] Wang K, Dong X, Chen Z, He Y, Xu Y, Liu Z. Highly selective synthesis of paracresol by conversion of anisole on ZSM-5 zeolites. Microporous Mesoporous Mater 2014;185:61-5. doi:10.1016/j.micromeso.2013.11.007.

588

[15] Cornella J, Gómez-Bengoa E, Martin R. Combined experimental and theoretical 589 study on the reductive cleavage of inert C-O bonds with silanes: Ruling out a classical $\mathrm{Ni}(0) / \mathrm{Ni}(\mathrm{II})$ catalytic couple and evidence for $\mathrm{Ni}(\mathrm{I})$ intermediates. J Am Chem Soc 2013;135:1997-2009. doi:10.1021/ja311940s.

592

[16] Mackie CJ, Doolan RK, Nelson FP. Kinetics of the thermal decomposition of 593 methoxybenzene(anisole). J Phys Chem C 1989;93:664-70. doi:0022365418912093-0664\$01.50/0 Lin.

595

[17] Song Q, Wang F, Cai J, Wang Y, Zhang J, Yu W, et al. Lignin depolymerization 596 (LDP) in alcohol over nickel-based catalysts via a fragmentation-hydrogenolysis process. Energy Environ Sci 2013;6:994. doi:10.1039/c2ee23741e.

598 599

600

601

[18] Saidi M, Samimi F, Karimipourfard

D, Nimmanwudipong T, Gates BC, Rahimpour MR. Upgrading of lignin-derived bio-oils by catalytic hydrodeoxygenation. Energy Environ Sci 2014;7:103-29. doi:10.1039/C3EE43081B.

[19] Zhu X, Lobban LL, Mallinson RG, Resasco DE. Bifunctional transalkylation and 603 604 hydrodeoxygenation of anisole over a Pt/HBeta catalyst. J Catal 2011;281:21-9. doi:10.1016/j.jcat.2011.03.030.

605

[20] Runnebaum RC, Nimmanwudipong T, Block DE, Gates BC. Catalytic conversion 606 of compounds representative of lignin-derived bio-oils: a reaction network for 607 guaiacol, anisole, 4-methylanisole, and cyclohexanone conversion catalysed by 608 Pt/Y-Al2O3. Catal Sci Technol 2012;2:113-8. doi:10.1039/C1CY00169H. 
Catalytic Reforming of Anisole. Chinese J Chem Phys 2010;23:693-700. doi:10.1088/1674-0068/23/06/693-700.

612 [22] González-Borja MA, Resasco DE. Anisole and Guaiacol Hydrodeoxygenation 613 over Monolithic Pt-Sn Catalysts. Energy \& Fuels 2011;25:4155-62. doi:10.1021/ef200728r.

[23] Mu W, Ben H, Ragauskas A, Deng Y. Lignin Pyrolysis Components and Upgrading-Technology Review. Bioenergy Res 2013;6:1183-204. doi:10.1007/s12155-013-9314-7.

618

[24] Jin S, Xiao Z, Li C, Chen X, Wang L, Xing J, et al. Catalytic hydrodeoxygenation 619

620 of anisole as lignin model compound over supported nickel catalysts. Catal Today 2014;234:125-32. doi:10.1016/j.cattod.2014.02.014.

621

[25] Laurent E, Delmon B. Study of the hydrodeoxygenation of carbonyl, carboxylic 622 623 and guaiacyl groups over sulfided CoMo/y-Al2O3 and NiMo/y-Al2O3 catalyst. Appl Catal A Gen 1994;109:97-115. doi:10.1016/0926-860X(94)85005-4.

624

[26] Mukundan S, Konarova M, Atanda L, Ma Q, Beltramini J. Guaiacol 625 hydrodeoxygenation reaction catalyzed by highly dispersed, single layered MoS 2/C. Catal Sci Technol 2015;5:4422-32. doi:10.1039/C5CY00607D.

627

[27] Khromova SA, Smirnov AA, Bulavchenko OA, Saraev AA, Kaichev V V., 628 629 Reshetnikov $\mathrm{SI}$, et al. Anisole hydrodeoxygenation over $\mathrm{Ni}-\mathrm{Cu}$ bimetallic catalysts: The effect of $\mathrm{Ni} / \mathrm{Cu}$ ratio on selectivity. Appl Catal A Gen 2014;470:261-70. doi:10.1016/j.apcata.2013.10.046.

631

[28] Smirnov A, Khromova S, Bulavchenko O, Kaichev V, Saraev A, Reshetnikov S, 632 et al. Effect of the $\mathrm{Ni} / \mathrm{Cu}$ ratio on the composition and catalytic properties of 633 nickel-copper alloy in anisole hydrodeoxygenation. Kinet Catal 2014;55:69-78. doi:10.1134/S0023158414010145. 
635 [29] Pichaikaran S, Arumugam P. Vapour phase hydrodeoxygenation of anisole over ruthenium and nickel supported mesoporous aluminosilicate. Green Chem 2016;18:2888-99. doi:10.1039/C5GC01854D.

638

[30] Ghampson IT, Pecchi G, Fierro JLG, Videla A, Escalona N. Catalytic 639

640 hydrodeoxygenation of anisole over Re-MoO x /TiO 2 and Re-VO x /TiO 2 $\begin{array}{llll}\text { catalysts. } & \text { Appl } & \text { Catal } & \text { B }\end{array}$ Environ $2017 ; 208: 60-74$. doi:10.1016/j.apcatb.2017.02.047.

642 [31] Alonso DM, Wettstein SG, Dumesic JA. Bimetallic catalysts for upgrading of 643 biomass to fuels and chemicals. Chem Soc Rev 2012;41:8075. doi:10.1039/c2cs35188a.

645

[32] Zhang J, Fidalgo

B, Kolios A, Shen

D, Gu S. Mechanism of deoxygenation in 646 anisole decomposition over single-metal loaded HZSM-5: Experimental study. Chem Eng J 2018;336:211-22. doi:10.1016/j.cej.2017.11.128.

648

[33] Zhang J, Fidalgo B, Shen D, Zhang X, Gu S. Mechanism of hydrodeoxygenation 649 (HDO) in anisole decomposition over metal loaded Brønsted acid sites: Density 650 Functional Theory (DFT) study. Mol Catal 2018;454:30-7. 651 doi:10.1016/j.mcat.2018.05.015.

652

[34] Whiffen VML, Smith KJ, Straus SK. The influence of citric acid on the synthesis 653 654 and activity of high surface area MoP for the hydrodeoxygenation of 4methylphenol. Appl Catal A Gen 2012;419-420:111-25. 655 doi:10.1016/j.apcata.2012.01.018.

[35] Nie L, De Souza PM, Noronha FB, An W, Sooknoi T, Resasco DE. Selective 657 conversion of $\mathrm{m}$-cresol to toluene over bimetallic Ni-Fe catalysts. J Mol Catal A Chem 2014;388-389:47-55. doi:10.1016/j.molcata.2013.09.029. 
660

661

662

663

664

665

666

667

668

669

670

671

672

673

674

675

676

677

678

679

680

681

682

683

production via catalytic steam reforming of m-cresol over Ni-Fe/HZSM-5 catalyst. Mod Chem Ind 2016;36:146-9. doi:10.16606/j.cnki.issn0253-4320.2016.08.035.

[37] Özdemir E, Yeniova H, Alibeyli R. Catalytic Conversion of a Mesitylene and n Decane Mixture in the Presence of Hydrogen Over ZSM-5 Based Catalysts. Pet Sci Technol 2014;32:1598-606. doi:10.1080/10916466.2012.668155.

[38] Smirnov A, Khromova S, Ermakov DY, Bulavchenko O, Saraev A, Aleksandrov $\mathrm{P}$, et al. The composition of $\mathrm{Ni}-\mathrm{Mo}$ phases obtained by NiMoOx-SiO2 reduction and their catalytic properties in anisole hydrogenation. Appl Catal A Gen 2016;514:224-34. doi:10.1016/j.apcata.2016.01.025.

[39] Rensel DJ, Rouvimov S, Gin ME, Hicks JC. Highly selective bimetallic FeMoP catalyst for C-O bond cleavage of aryl ethers. J Catal 2013;305:256-63. doi:10.1016/j.jcat.2013.05.026.

[40] Fogler HS. Chemical Reactors. vol. 168. Washington, D.C: American Chemical Society; 1981. doi:10.1021/bk-1981-0168.

[41] Delley B. An all-electron numerical method for solving the local density functional for polyatomic molecules. J Chem Phys 1990;92:508-17. doi:10.1063/1.458452.

[42] Delley B. From molecules to solids with the DMol3 approach. J Chem Phys 2000;113:7756. doi:10.1063/1.1316015.

[43] Elanany M, Koyama M, Kubo M, Selvam P, Miyamoto A. Periodic density functional investigation of Bronsted acidity in isomorphously substituted chabazite and AIPO-34 molecular sieves. Microporous Mesoporous Mater 2004;71:51-6. doi:10.1016/j.micromeso.2004.03.018.

[44] Kalita B, Deka RC. DFT study of CO adsorption on neutral and charged Pdn(n = 1-7) clusters. Eur Phys J D 2009;53:51-8. doi:10.1140/epjd/e2009-00044-6. 
684 [45] Perdew JP, Burke K, Ernzerhof M. Generalized Gradient Approximation Made Simple. Phys Rev Lett 1996;77:3865-8. doi:10.1103/PhysRevLett.77.3865.

686

687

688

689

690

691

692

693

694

695

696

697

698

699

700

701

702

703

704

705

706

707

708

[46] Grimme S. Semiempirical GGA-type density functional constructed with a longrange dispersion correction. J Comput Chem 2006;27:1787-99. doi:10.1002/jcc.20495.

[47] Bredenberg JB-S, Huuska M, Räty J, Korpio M. Hydrogenolysis and hydrocracking of the carbon-oxygen. J Catal 1982;77:242-7.

[48] Wang J, Jin L, Li Y, Hu H. Preparation of Fe-Doped Carbon Catalyst for Methane Decomposition to Hydrogen. Ind Eng Chem Res 2017;56:11021-7. doi:10.1021/acs.iecr.7b02394.

[49] Martínez A, López C, Márquez F, Díaz I. Fischer-Tropsch synthesis of hydrocarbons over mesoporous Co/SBA-15 catalysts: the influence of metal loading, cobalt precursor, and promoters. J Catal 2003;220:486-99. doi:10.1016/S0021-9517(03)00289-6.

[50] González O, Pérez H, Navarro P, Almeida LC, Pacheco JG, Montes M. Use of different mesostructured materials based on silica as cobalt supports for the Fischer-Tropsch synthesis. Catal Today 2009;148:140-7. doi:10.1016/j.cattod.2009.03.030.

[51] Ardiyanti AR, Khromova SA, Venderbosch RH, Yakovlev VA, Heeres HJ. Catalytic hydrotreatment of fast-pyrolysis oil using non-sulfided bimetallic $\mathrm{Ni}-\mathrm{Cu}$ catalysts on a $\delta$-Al2O3 support. Appl Catal B Environ 2012;117-118:105-17. doi:10.1016/j.apcatb.2011.12.032.

[52] Hernández JMG, Anota EC, de la Cruz MTR, Melchor MG, Cocoletzi GH. First principles studies of the graphene-phenol interactions. J Mol Model 2012;18:3857-66. doi:10.1007/s00894-012-1382-7. 
709 [53] Honkela ML, Björk J, Persson M. Computational study of the adsorption and dissociation of phenol on $\mathrm{Pt}$ and Rh surfaces. Phys Chem Chem Phys 2012;14:5849. doi:10.1039/c2cp24064e.

712

[54] Wang

$\mathrm{R}$, Zhang

D, Liu

C. DFT study of the adsorption of $2,3,7,8-$ tetrachlorodibenzo-p-dioxin on pristine and $\mathrm{Ni}$-doped boron nitride nanotubes. Chemosphere 2017;168:18-24. doi:10.1016/j.chemosphere.2016.10.050.

[55] Hensley AJR, Wang Y, McEwen J-S. Adsorption of phenol on Fe (110) and Pd 716 $(111)$ from firs principles.

Surf Sci 2014;630:244-53. doi:10.1016/j.susc.2014.08.003. 